\title{
Volunteer Blood Donor Search System Kiosk based on Distributed Database
}

\author{
Md.Mukhtar Md.Yakub \\ Lecturer, C.S Dept, \\ SSBES's ITM, Nanded.
}

\author{
Mr. Mahesh S. Darak \\ Lecturer, C.S Dept, \\ SSBES's ITM, Nanded.
}

\author{
Miss. Geetanjali M. Vaidya \\ Lecturer, C.S Dept, \\ SSBES's ITM, Nanded.
}

\begin{abstract}
There are wide range of applications and context where Communication \& DBMS techniques are used separately. Also with the high speed development of mutually dependent techniques, Internetworking has grown and still at the speed higher than Radio and Computer technologies. Database techniques since decades proved it prominence in storing and handling large volume of data efficiently. Blood bank is one social organization playing vital role in saving human life in a case if a person needs blood to save either his own life or somebody else.
\end{abstract}

\section{General Terms}

Distributed Database

\section{Keywords}

kiosk, distributed database, multimedia, HTML, BGDBS, BGDBC

\section{INTRODUCTION}

A database system in which data is physically stored across several sites, and each site is typically managed by a DBMS that is capable of running independently of the other sites ${ }^{[1]}$.

Such physically distributed databases can be connected with each other using high speed communication links of internet.

Distributed Database are used. In this the data is segmented on multiple sites.

A database system in which data is physically stored across several sites ${ }^{[4]}$, and each site is typically managed by a DBMS that is capable of running independently of the other sites.

Distributed Database characteristics ${ }^{[5]}$ :

i] Transparent Data Distribution

ii] Distributed data independence

iii] Distributed transaction atomicity

\section{WHAT IS BLOOD BANK}

Blood Bank/ Blood Centre is defined as a building or location specifically dedicated to blood collection, component production, testing, storage, distribution, etc ${ }^{[8]}$.

Basic functions of a blood transfusion centre are:

- $\quad$ Organizing the service

- Recruitment of donors

- Collection, processing, storage and distribution of blood and blood components
- Laboratory investigations

- Participation in clinical use of blood and blood components

- Teaching and training

- $\quad$ Research and development

\section{BLOOD REQUIREMENT FACTS}

Following are the prominent situations in which a person may need supplementary blood ${ }^{[9]}$ :

\begin{tabular}{|l||l|}
\hline 1. Automobile Accident & 50 units of blood \\
\hline \hline 2. Heart Surgery & $\begin{array}{l}6 \text { units of blood / 6 units } \\
\text { of platelets }\end{array}$ \\
\hline \hline 3. Organ Transplant & $\begin{array}{l}40 \text { units of blood / 30 } \\
\text { units of platelets }\end{array}$ \\
\hline 4. 20 bags of cryoprecipitate & $\begin{array}{l}25 \text { units of fresh frozen } \\
\text { plasma }\end{array}$ \\
\hline 5. Bone Marrow Transplant & $\begin{array}{l}120 \text { units of platelets/ 20 } \\
\text { units of blood }\end{array}$ \\
\hline 6. Burn Victims & 20 units of platelets \\
\hline
\end{tabular}

\section{PRESENT SCENARIO}

If a patient who severely suffers from blood loss due to any reason and needs blood then either the hospital supplies the blood required. If blood is not available at hospital then it ask volunteer donors to donate the blood. But in this case it is very critical that the blood to be denoted must be of same group that of the patient requiring it. In case if no match then a search operation is carried out and also the relatives or accompanying person of patient need to approach the blood bank. If the blood bank having required group of blood they again ask for substitute.

In second case, if a donor of matching blood group found, still the donor has to undergo various types test for his blood and also background details of donor like his weight, age, Hemoglobin, pulse, temperature, health condition and last date of blood donation, etc to be collected. This complete process is very time consuming and a patient battling for his life in critical condition this time period is very vital. 
At present there is no such fully automated system in various states of India to find appropriate blood donor. In most of the cases, the hospitals and blood banks either operating manually or even if using an automated system, the specific and required data can not be easily filtered. A person searching for volunteer blood donor faces many challenges to get the donor of appropriate blood group. The working of the present system can be shown as:

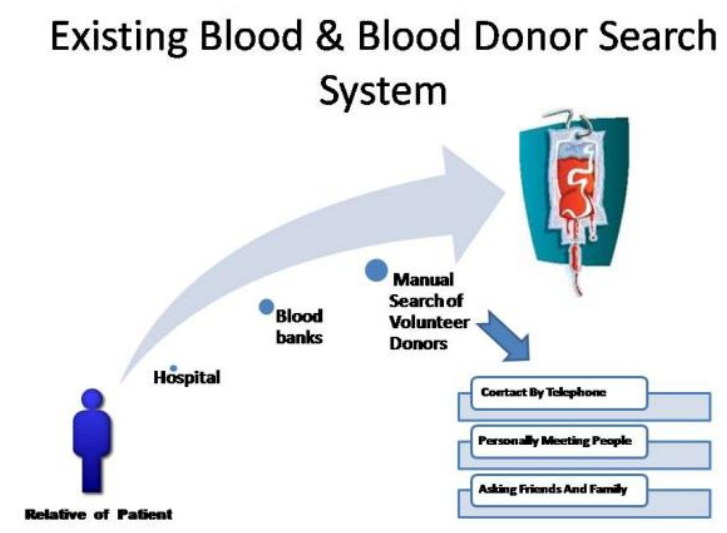

\section{PROPOSED SYSTEM}

To speed up this process of finding donor of matching blood group and collecting blood a distributed database system is suggested which can be accessed by kiosk. In information technology, a kiosk (pronounced KEE-ahsk ) is a small physical structure often including a computer and a display screen that displays information for people walking by. Kiosks are common near the entrances of shopping malls provide shoppers with directions. Kiosks are also used at trade shows and professional conferences. The word is of Turkish and earlier Persian origin, where it meant an outdoor pavilion or a portico.

More sophisticated kiosks let users interact and include touch screens, sound, and motion video. A number of companies specialize in creating multimedia kiosks. A simple kiosk can be created using HTML pages and graphics, setting the type size large enough to attract people from a short distance, and removing the Web browser's tool bar so that the display screen is effectively in "kiosk mode." The presentation can be designed to simply loop through a series of pages or to allow user interaction and exploration. Having a separate printed sign that invites people to your home-made kiosk may help. Also a kiosk with simply Black and White monitor or Color display can be used.

The proposed system can be represented as:

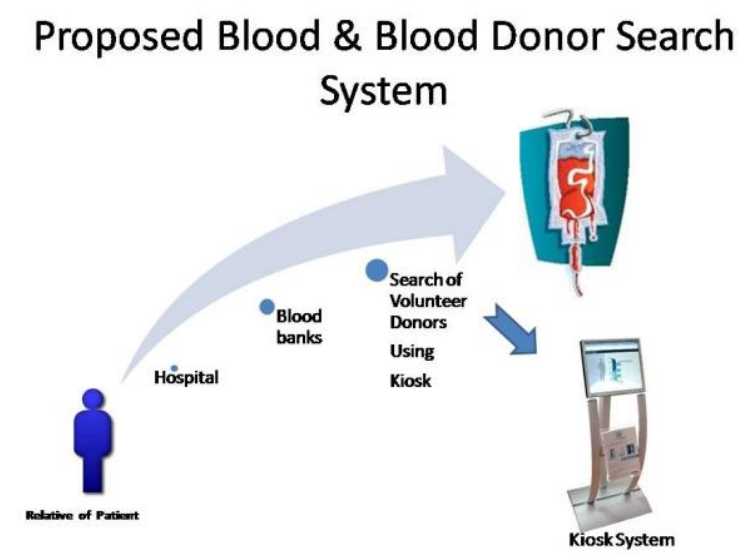

6. TECHNICAL ASPECTS

This complete system may comprise server, client and network connecting both systems as:

i) BGDBS - Blood Group Database Server

The blood group database can be physically distributed city wise and the server can be placed at universities of that city.

In case a university covering many cities, the server can be setup at either Government Hospital or one of the blood banks. The server will be collecting data from various colleges and college is collecting and uploading this data to server at the time of admission process.

ii) BGDBC - Blood Group Database Client

The clients of this database server can be setup at all the hospitals and commonly accessed public places.

iii) Network Connection

As like ATMs setup at various public places and connected with bank servers, similarly these BGDBS and BGDBCs can be connected with the help of either telephone lines or wireless $3 \mathrm{G}$ enabled communication services.

The architecture of Distributed Database of Blood Bank system can be represented as:

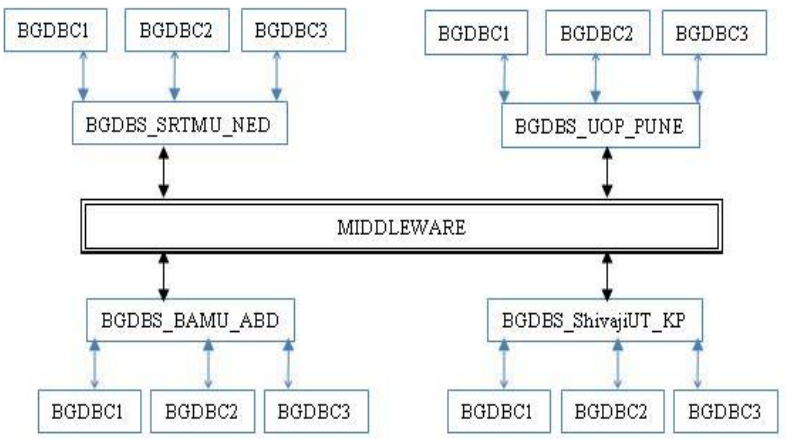

Fig.4 -Architecture of BGDBS-BGDBC with Middleware 


\section{SETUP REQUIREMENTS}

- The Kiosk is planned to have about 200 Sq. ft. Floor Area.

- Computer hardware and software proposed for the Kiosk with approximate cost involved are as below:

\begin{tabular}{|l|l|l|l|l|}
\hline Sr. No & Item & $\begin{array}{l}\text { Quantity } \\
\text { (In N os) }\end{array}$ & $\begin{array}{l}\text { Unit } \\
\text { Price } \\
\text { (INR) }\end{array}$ & $\begin{array}{l}\text { Total } \\
\text { Price } \\
\text { (INR) }\end{array}$ \\
\hline & Computer & 1 & $\mathbf{3 0 , 0 0 0}$ & $\mathbf{3 0 0 0 0}$ \\
\hline & $\begin{array}{l}\text { UUS } \\
\text { (1KVA) }\end{array}$ & 1 & $\mathbf{5 0 0 0}$ & $\mathbf{5 0 0 0}$ \\
\hline
\end{tabular}

- A telephone link

- A provision for $1 \mathrm{KVA}$ Generator Set may be kept to run the KIOSK in absence of normal electric supply.

- Site Preparation like partitioning, painting, electrical wiring, electrical earthing if necessary, false-roofing and telephone connection can be completed within a cost of Rs.30,000/-.

\section{Alternatively existing ATM sites can be used.}

\section{WORKING}

In this a regularly updated database is designed having various details of people including donors and non-donors (person yet not donated blood single time). The required data for this database can be collected from various colleges and educational institutions as these institutions are the potential pool of large volume of data.

Again this data to be used at ease can be divided on the basis of city. Database of single city can store records as:

\section{College : SSBES's ITM Nanded College Code:148}

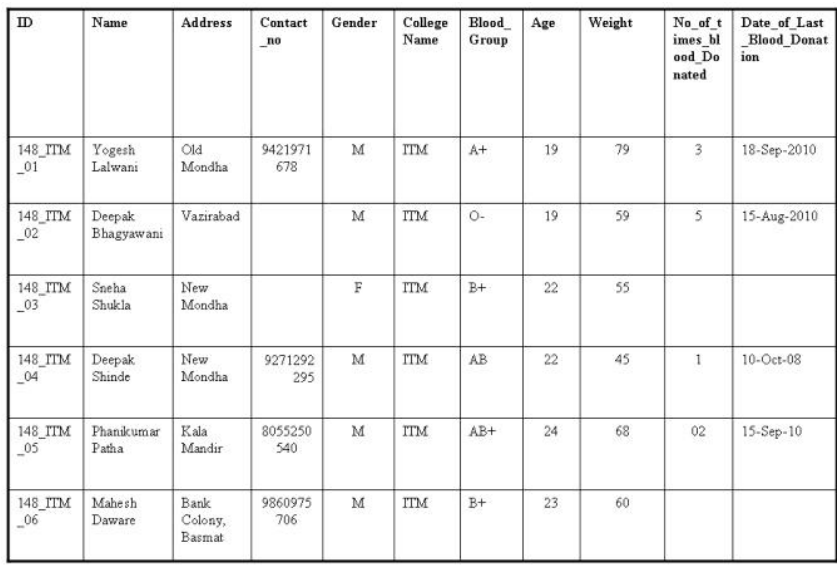

College : NES's SCN Nanded

College Code: 103

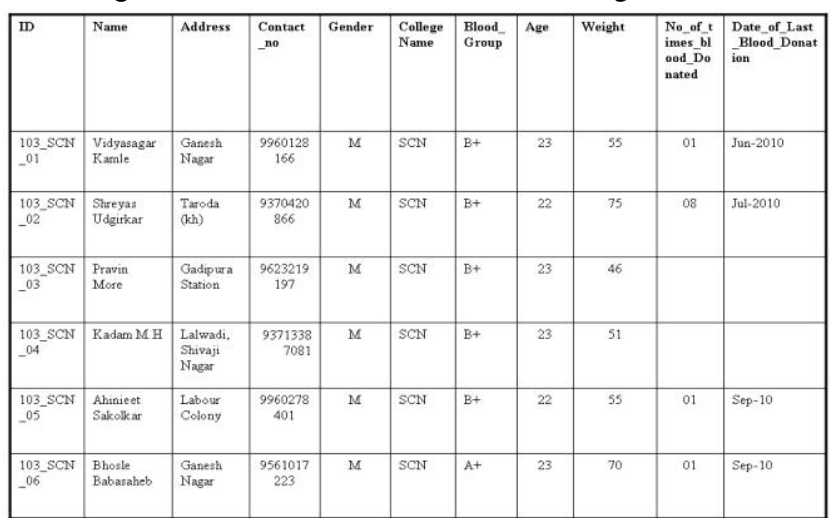

Table.1 - Sample Database Table

To provide a unique ID to each student, the ID attribute will have value composed of College code, 3 letters abbreviation of college Name and integer as:

\section{College Code_CLG_INT \\ Eg.148_ITM_01}

The reason for using college code in this ID is that college code assigned to one college under one university is unique.

With the availability of high speed, high storage capacity and low cost computers along with networking and communication technology the BGDBS can be connected with several BGDBCs set up at various public places like hospitals, railway stations, near to ATMs etc. BGDBS are set up at Universities, Govt. Hospitals, etc and these physically separated BGDBSs can be connected with each other through high speed telephone lines or wireless media.

Whenever a user needs to find the person of required matching blood group he/she can walk up to any of nearest BGDBC. This BGDBC having a user friendly GUI as like on ATM or KIOSK at railway station.

With the help of this user interface a person can generate the list of eligible potential donors of required blood group. As the database is storing details of each student including his or her address, contact number which is very useful to contact the appropriate person for blood donation. Also, if the student is regular donor, the information about the last_date_of_blood_donation helps to decide weather to approach and request a person because as per the recommendation a Male can re-donate a blood after 56 days. 
Also it is found that, the Hemoglobin level is considered at the time of blood donation which may get decreases due to fear if the person is donating the blood first time. In such case no_of_times_blood_donated field gives valuable information weather to prefer a person who is having past experience of blood donation.

\section{FUTURE PROSPECTS}

There may be chances of ambiguity creeping in ID. To overcome this, use of UID is suggested. As the ambitious project of Central Govt. of India, very soon will be providing a UID to each Indian citizen and same UID can serve as unique identifier. In future this database can be so updated that, to all the existing donor a "DONOR ID" can be given which will serve as unique identifier. With the help of this DONOR ID information about a donor such as no_of_times_blood_donated and date_of_last_blood_donation can be updated from any BGDBC.

\section{CONCLUSION}

Blood is life saving element and human blood have no substitute. No where it can be manufactured, it can only be collected by generous blood donation. When every walk of life is enjoying and experiencing computers and computer based technology, why not the Blood Bank? Distributed Database by it's virtue of physical separation and connection can play essential role in collecting the donors and potential donors data and disseminating to everyone in need.

\section{ACKNOWLEDGMENTS}

We sincerely express our gratitude to all those friends and dear students who extended their unconditional and continuous support for the completion of this paper.

\section{REFERENCES}

[1] R. Abbott and H. Garcia-Molina. Scheduling real-time transactions: a performance evaluation. ACM Transactions on Database Systems, 17(3), 1992.

[2] S. Abiteboul. Querying semi-structured data. In Intl. Conf. on Database Theory, 1997.

[3] S. Abiteboul, R. Hull, and V. Vianu. Foundations of Databases. Addison-Wesley, 1995.

[4] D. Quass, A. Gupta, I.S. Mumick, and J. Widom. Making Views Self-Maintainable for Data Warehousing, Proc. of Fourth Intl. Conf. on Parallel and Distributed Information Systems (PDIS '96), December 1996.

[5] Gerald Bernbom, Data Administration and Distributed Data Processing (Cause/Effect Vol. 14, Number 4, Winter 1992. Accessed 26 September 2000) available from http://www.lessaworld.com/dm/dm02.txt Internet6.

[6] Distributed Data Processing (Accessed 26 September 2000) available from http://www.bus.okstate.edu/lhammer/AISweb/AIS9.HTM

[7] Chen, M.S., Han, J., and Yu, P.S., Data Mining: An Overview from Database Perspective, In IEEET Trans.on Knoledge and Data Engineering, 8(6), 866-883,1996

[8] Voluntary Blood Donation Programme - an operational Guideline, National AIDS Control Organisation, Ministry of Health and Family Welfare, Government of India, New Delhi.

[9] 52 Facts About Blood Donation, The 2005 Nationwide Blood Collection and Utilization Survey Report, Department of Health and Human Services. 